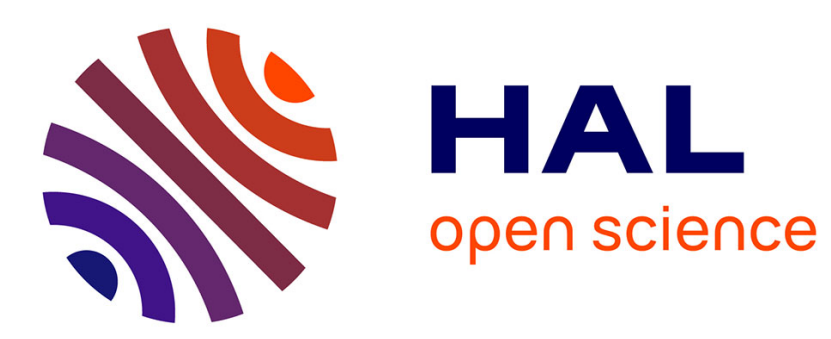

\title{
Is Investment Time Irreversible? Some Empirical Evidence for Disaggregated UK Manufacturing Data
}

\author{
Alan Speight, Piers Thompson
}

\section{To cite this version:}

Alan Speight, Piers Thompson. Is Investment Time Irreversible? Some Empirical Evidence for Disaggregated UK Manufacturing Data. Applied Economics, 2006, 38 (19), pp.2265-2275. 10.1080/00036840500427551 . hal-00581905

\section{HAL Id: hal-00581905 \\ https://hal.science/hal-00581905}

Submitted on 1 Apr 2011

HAL is a multi-disciplinary open access archive for the deposit and dissemination of scientific research documents, whether they are published or not. The documents may come from teaching and research institutions in France or abroad, or from public or private research centers.
L'archive ouverte pluridisciplinaire HAL, est destinée au dépôt et à la diffusion de documents scientifiques de niveau recherche, publiés ou non, émanant des établissements d'enseignement et de recherche français ou étrangers, des laboratoires publics ou privés. 


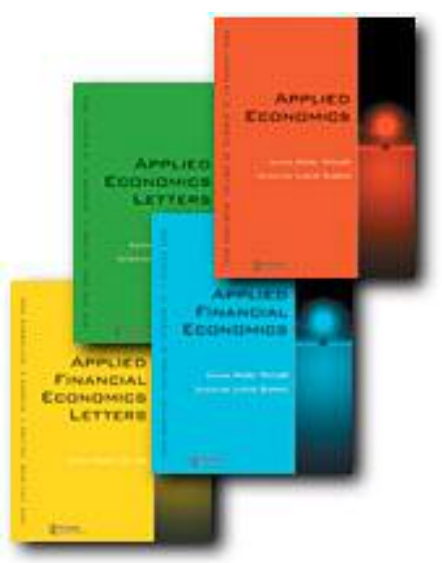

Is Investment Time Irreversible? Some Empirical Evidence for Disaggregated UK Manufacturing Data

\begin{tabular}{|c|c|}
\hline Journal: & Applied Economics \\
\hline Manuscript ID: & APE-05-0028.R1 \\
\hline Journal Selection: & Applied Economics \\
\hline $\begin{array}{r}\text { Date Submitted by the } \\
\text { Author: }\end{array}$ & 28-Apr-2005 \\
\hline JEL Code: & $\begin{array}{l}\text { C10 - General < C1 - Econometric and Statistical Methods: General } \\
\text { < C - Mathematical and Quantitative Methods, E22 - } \\
\text { Capital|Investment (including Inventories)|Capacity < E2 - } \\
\text { Consumption, Saving, Production, Employment, and Investment < } \\
\text { E - Macroeconomics and Monetary Economics, E32 - Business } \\
\text { Fluctuations|Cycles < E3 - Prices, Business Fluctuations, and Cycles } \\
<\text { E - Macroeconomics and Monetary Economics, L60 - General < L6 } \\
\text { - Industry Studies: Manufacturing < L - Industrial Organization }\end{array}$ \\
\hline Keywords: & Time Irreversibility, Nonlinearity, Investment, Disaggregated Data \\
\hline
\end{tabular}




\title{
Is Investment Time Irreversible? Some Empirical Evidence for Disaggregated UK Manufacturing Data
}

\author{
Alan E H Speight* \\ Department of Economics \\ University of Wales Swansea \\ $\&$ \\ Piers Thompson \\ Department of Economics \\ University of Wales Swansea
}

\section{December 2004}

\begin{abstract}
$\underline{\text { Abstract }}$
It has long been suggested that investment may be time irreversible, and consideration of the option value of waiting to invest has aroused renewed interest in this issue. This paper tests for time irreversibility in UK investment according to disaggregation by type of investment expenditure and across manufacturing sector groupings. The test results reported indicate that the irreversibility of investment patterns varies not only from industry to industry but also according to the type of capital being purchased, with significant time irreversibility detected in gross fixed capital formation and aggregate vehicles expenditure, and industrial sector groupings comprising fuels \& oil refining, engineering \& vehicles, and textiles \& leather. However, only in the first and last of these series is time irreversibility attributable to non-linearities in the underlying data generating process, and consistent with threshold effects which may be associated with (S,s) type models of investment dynamics.
\end{abstract}

Keywords: Time Irreversibility; Nonlinearity; Investment; Disaggregated Data.

JEL: C10; E22; E32; L60.

*Corresponding author: Prof. Alan Speight, Department of Economics, School of Business \& Economics, University of Wales Swansea, SA2 8PP, UK

Tel: (01792) 295168. Fax: (01792) 295872

e-mail: a.speight@swan.ac.uk 


\section{Introduction}

Interest in the possibility of economic time series displaying asymmetric behaviour over the course of the business cycle is long-standing (Mitchell 1927; Keynes 1936; Burns and Mitchell 1946), and this interest has been formalized statistically in more recent years with the development of a variety of procedures for the statistical testing of business cycle asymmetry (Neftci, 1984; DeLong and Summers, 1996; Sichel, 1993; McQueen and Thorley, 1993; Ramsey and Rothman, 1996, Verbrugge, 1997; Hinich and Rothman, 1998; Psaradakis, 2000). Applications of these test procedures have been widespread and varied, and have included, for example, applications to international industrial production and other coincident business cycle indicator data (Speight, 1997; Adreano and Savio, 2002; Pieró, 2004), national macroeconomic data (Mills, 1995; Stanca, 1999; Cook, 2000; Bodman, 2001; Olekalns, 2001), inflation data (Verbrugge, 2002) and consumers' expenditure data in particular (Holly and Stannett, 1995; Speight and McMillan, 1997; Cook, 2000a. 2000b; 2000c). In distinction from more general business cycle modelling, the latter applications are in part motivated by the well-recognized distinction in theoretical models between consumers' expenditure and consumption as a service flow from a stock of goods and services, such that the purchase of durables may be more closely related to investment theory than consumption theory. Indeed, theoretical models of investment asymmetry are well developed, based on the 'option value of waiting to invest' and the resulting 'irreversible' nature of investment under uncertainty (Pindyck, 1988; Dixit, 1992; Dixit and Pindyck, 1994; Abel and Eberly, 1996; Vandenbroucke, 1999). As potentially the most volatile component of aggregate expenditure, and in view of the attendant consequences for simulation exercises and the policy implications of such asymmetries being incorporated into the sectoral relationships embodied in large scale macroeconometric models, it is therefore perhaps of some surprise that the 
potentially asymmetric, and specifically time-irreversible, properties of investment have not received closer scrutiny in the empirical literature. ${ }^{1}$

In view of the foregoing considerations, this paper provides an empirical examination of time irreversible asymmetry in UK investment data at the aggregate and disaggregated industry level through application of the time reversibility test introduced by Ramsey and Rothman (1996), which possesses appealing properties in the current context. In addition to characterizing the nature of asymmetric adjustment in investment, the test has the particular advantage of enabling discrimination between time reversibility which is driven by a nonlinear data generating process, in which case a non-linear model, possibly of threshold autoregressive form may be appropriate, and time reversibility which is instead driven by innovations drawn from a non-Gaussian probability distribution in the presence of a linear data generating process. Further, the test has power in discriminating between certain classes of nonlinear model, in particular the bilinear extension of the linear ARIMA model and the threshold autoregressive model.

The remainder of this paper is organised as follows. Section II provides an overview of the concept of the option value of waiting to invest and its implications for the lumpy and time irreversible nature of investment, and the associated potential for nonlinear dynamics of threshold form. Section III describes the statistical concept of time reversibility and the associated test procedure for time irreversibility and its underlying form. The data to be examined are discussed in Section IV, while Section V reports the time irreversibility test

\footnotetext{
${ }^{1}$ Notable exceptions to this remark are provided by the work of Price $(1995,1996)$, who examines the consequences of aggregate uncertainty for capacity utilisation and investment, and demonstrates in particular the existence of asymmetric adjustment dynamics governing UK manufacturing sector investment in the context of a non-linear time series model exhibiting threshold effects. Relatedly, Sensier (2003) investigates the asymmetric properties and time-series behaviour of UK manufacturing inventories and production over the business cycle in the context of a model of asymmetric adjustment, as well as providing test statistics for the asymmetric properties of that data.
} 
results in application to the aggregate and disaggregate UK investment series considered. Section VI summarizes the findings and conclusions of the paper.

\section{Irreversible Investment}

Capital adjustment costs were first introduced into neoclassical investment theory by Eisner and Strotz (1963) in order to preclude the possibility of infinite rates of investment and, for simplicity, these adjustment costs were assumed to take a symmetric convex form. ${ }^{2}$ The incompatibility of such assumed adjustment costs with the patterns observed in investment data subsequently encouraged authors such as Rothschild (1971) to develop investment functions with linear piecewise or fixed adjustment cost components. The assumption of this type of adjustment cost results in firms only undertaking investments (disinvestments) when the desired capital stock is a certain level above (below) the actual capital stock. In extension of this approach, '(S,s)' models such as those initially developed by Dixit (1991) and Abel and Eberly $(1996,1997)$ attempt to model the way firms operate in three regimes: invest, don't invest, and divest.

Why should capital adjustment costs include a fixed component? One suggestion is that investment is at least partially irreversible. Thus, once made, a firm cannot immediately retrieve the whole cost of an investment. The explanations typically offered for this irreversibility of investment are that it is due either to investments being firm or industry specific, or firms facing a 'lemon's' style problem when reselling capital (Akerlof 1970). Whilst the potential irreversibility of investment is not a new concept, with a number of authors having previously drawn attention to the difficulty firms face in reselling capital

\footnotetext{
${ }^{2}$ Lucas (1967), Gould (1968) and Mussa (1977) also provide important contributions to the subject of capital adjustment costs, particularly the separation of costs associated with capital good supply (external) and disruption costs to the firm (internal). It should also be noted that Eisner and Strotz recognized the potential inadequacy of symmetric costs, and appreciated that adjustment costs may indeed be asymmetric in practice.
} 
equipment once acquired (see for example, Arrow 1968), the introduction of the 'option value of waiting to invest' from the finance literature has reinvigorated interest in this area of research (Bernanke, 1983; McDonald and Siegel, 1986; Dixit and Pindyck, 1994; Pindyck, 1988). In particular, if investment is irreversible, there is a return to waiting. Hence, a firm will only invest if the value of an investment is at least equal to the value of waiting for further information or better investment opportunities to become available (the option value of waiting to invest at a later date). ${ }^{3}$

The empirical consequence of investment being irreversible should be that, rather than smoothing capital accumulation through time to move towards a new optimum level of capital (as would be the case under standard neo-classical theory), investment will instead be undertaken discretely in time, leading to spikes or 'lumpiness' in investment. More generally, the aggregate effect of firms making 'lumpy' investments under $(\mathrm{S}, \mathrm{s})$ rules at the microeconomic level will depend upon whether these investments are clustered in time or across industrial sectors. If the factors that induce firms to invest are wholly idiosyncratic there is likely to be little affect upon the patterns of aggregate or industry investment (Bertola and Caballero, 1994; Caballero et al., 1995). ${ }^{4}$ However, if investment inducing shocks occur predominantly at the industry or aggregate level then the bunching of firms' investment

3 See, for example, Dixit and Pindyck (1994) for a review of this earlier literature, and Caballero and Pindyck (1996) for an examination of the effects of irreversible investment on total investment and firm entry in a competitive industry subject to both industry-wide and idiosyncratic uncertainty. Relatedly, Gale (1996) has demonstrated that where the profitability of investment is dependent on the level of economic activity, the resulting incentive to delay investment in a recession may deepen the recession and lengthen the period of economic recovery. Abel and Eberly (1997) have shown that irreversible investment in the presence of convex costs leads to regions of behaviour in which investment in a homogeneous good is not responsive to Tobin's $q$, and other regions where it is. For extensions and empirical studies of the nonlinear relationship of investment to $q$, including regions of insensitivity, see for example Barnett and Sakellaris (1998) and Corrado et al. (2001). On the consequences of irreversible investment and idiosyncratic uncertainty for differences in firms' capital stocks and the aggregate capital stock in a dynamic general equilibrium setting model, see Jamet (2004). For a recent application of the real options methodology in the context of the valuation of agricultural investment decisions, see Tzouramani and Mattas (2004).

${ }^{4}$ In particular, Bertola and Caballero (1994) and Caballero et al. (1995) show that under certain distributional assumptions, and in the presence of a large amount of idiosyncratic microeconomic uncertainty in particular, there is likely to be little synchronisation at the aggregate level but the history of accumulated past shocks can nevertheless greatly affect the elasticity of investment response to future shocks. 
spikes is likely to produce much more pronounced peaks in the industry or aggregate investment pattern (Cooper et al., 1999). ${ }^{5}$ Alternatively, where firms face stochastic fixed adjustment costs, the typically sharp $(\mathrm{S}, \mathrm{s})$ rules are replaced a probability of adjustment (adjustment hazard) that responds smoothly to the firms' capacity gap, but yields nonlinear aggregate investment dynamics (Caballero and Engel, 1999). ${ }^{6}$ These considerations suggest that one way to empirically assess microeconomic investment irreversibility and its aggregate consequences is to test for the presence of time irreversibility in investment patterns at various levels of industrial sector aggregation, and in the aggregation of particular types of investment good expenditures. ${ }^{7}$

Moreover, the lumpiness of firms' investment patterns under the assumption of irreversible investment, as implied by $(\mathrm{S}, \mathrm{s})$ models, implies that some form of threshold model may be most appropriate for modelling investment. The most obvious class of time series model that would readily accommodate such behaviour in the modelling and forecasting of aggregate and industry level investment are of threshold autoregressive form, including threshold autoregressive (TAR), self-exciting threshold autoregressive (SETAR) and smooth transition autoregressive (STAR) models. However, the adoption of one or more of these non-linear models instead of some linear alternative may first depend on whether the

\footnotetext{
${ }^{5}$ For an interesting recent applied analysis of the within-industry coordination problem and strategic behaviour implications that may arise as the result of such lumpy investment patterns in the context of the British brick industry, see Wood (2005).

${ }^{6}$ More specifically, and in some parallel with option value of waiting approach, Caballero and Engel (1999) explain investment delays as the strategic response of firms' to heterogeneous adjustment hazards which have the capacity to either magnify or dampen the response of investment to an aggregate shock, depending on the shock size. The presence of such adjustment hazards implies asymmetry due to nonlinearity in aggregate investment, consistent with threshold effects, in that there are occasional sharp responses of investment to current or cumulative shocks.

${ }^{7}$ In the pursuit of evidence for such behaviour, Doms and Dunne (1998), for example, examine plant level investments in US manufacturing over the period 1973-1988 and find the distribution of investment rates to be symptomatic of irreversible investment, in that very few firms exhibit negative gross investment rates, whilst many firms group the majority of their investment in just three years of the sample period covered. The same study also found there to be a correlation between the number of investment spikes and the aggregate investment rate. In an interesting cliometric application of the Doms and Dunne methodology, Süssmuth (2003) similarly reports evidence of lumpiness and asymmetry as defining characteristics of German firm level capital adjustment patterns for the period 1880-1913.
} 
investment time series in question are empirically time reversible or not, which remains an open empirical question. ${ }^{8}$

\section{Time Irreversibility}

A dynamic stationary system is said to be time reversible if it is possible to substitute $-t$ for $t$ into the equation describing motion and leave the solution invariant, while the converse is true for a time irreversible system. ${ }^{9,} 10$ More formally, Ramsey and Rothman (1996) define the zero mean stationary time series $\left\{X_{t}\right\}$ as being time reversible if, the vectors $\left(X_{t_{1}}, X_{t_{2}}, \ldots, X_{t_{n}}\right)$ and $\left(X_{-t_{1}+m}, X_{-t_{2}+m}, \ldots, X_{-t_{n}+m}\right)$ have the same joint probability distributions for every positive integer $n$, every $t_{1}, t_{2}, \ldots, t_{n} \in R$, and all $m \in N$. In the presence of stationarity, the vectors $\left(X_{t_{1}}, X_{t_{2}}, \ldots, X_{t_{n}}\right)$ and $\left(X_{t_{n}}, X_{t_{n-1}}, \ldots, X_{t_{1}}\right)$ will also have the same joint probability distributions, which are assumed to be uniquely characterized by the respective sequence of moments and cross moments, such that time reversibility holds only if $E\left[X_{t}^{i} \cdot X_{t-k}^{j}\right]=E\left[X_{t}^{j} \cdot X_{t-k}^{i}\right]$ for all $i, j, k \in N$. The existence of a lag $k$ for which these two moments are not equal provides a sufficient though not necessary condition for time

\footnotetext{
${ }^{8}$ For further discussion of threshold models see Tong (1990).

${ }^{9}$ Ramsey and Rothman (1996) offer the time path of a round projectile in (windless) flight as an intuitive example of a time reversible process, and the dispersal of ink in water as an intuitive example of a time irreversible process. Investment aside, the diffusion of technology provides an obvious further example of a time irreversible economic process.

10 In relation to the extensive empirical literature concerned with testing for asymmetries in economic time series, time irreversibility therefore captures those measures of asymmetry that are 'longitudinal', whilst purely 'transversal' asymmetries are time reversible; in particular, longitudinal 'steepness' asymmetry is time irreversible, while transversal 'deepness' asymmetry is time reversible. These alternative definitions refer to differing speeds of adjustment in expansions and contractions; for example, the business cycle has long been thought to be characterised by steeper recessions and longer more gentle expansions. A particular advantage following from the representation of asymmetries in terms of time irreversibility, as noted in Section I, is that the formulation in terms of time irreversibility lends itself to a discriminating test between circumstances where the process innovations are asymmetric but the impulse transmission mechanism is linear, and circumstances where innovations are symmetric and the impulse transmission mechanism is nonlinear. In contrast, the representation of asymmetries in terms of 'steepness' associated with the properties of the third moment of a series distribution does not permit such discrimination. See Mittnik and Niu (1994) and Psaradakis (2000) for further discussion of a number of commonly employed tests of asymmetry.
} 
irreversibility, prompting Ramsey and Rothman to propose the a test procedure based on consideration of the difference between the symmetric bicovariances for a zero-mean stationary process:

$$
\gamma_{i, j}(k)=E\left[X_{t}^{i} \cdot X_{t-k}^{j}\right]-E\left[X_{t}^{j} \cdot X_{t-k}^{i}\right]
$$

such that $\left\{X_{t}\right\}$ is time reversible if $\gamma_{i, j}(k)=0$ for all $i, j, k \in N$. Given that the comparison of all bicovariances for a time series is impractical, a process is said to be time reversible to order $m$ and degree $K$ if $\gamma_{i, j}(k)=0$ under the limits $(i+j) \leq m$ and $k \leq K{ }^{11}$ The test statistics introduced by Ramsey and Rothman (1996) to test for time irreversibility are based on a method of moments sample estimator of the symmetric-bicovariance function in (1):

$$
\hat{\gamma}_{2,1}(k)=\hat{B}_{2,1}(k)-\hat{B}_{1,2}(k)
$$

where $\hat{B}_{2,1}(k)=(T-k)^{-1} \sum_{t=K+1}^{T} X_{t}^{2} \cdot X_{t-k}, \hat{B}_{1,2}(k)=(T-k)^{-1} \sum_{t=K+1}^{T} X_{t} X_{t-k}^{2}$ and $T$ denotes sample size. Standardizing by the small sample variance of $\hat{\gamma}_{2,1}(k)$ then yields the $T R(k)$ statistic for a given lag order, $k$, as:

$$
\operatorname{TR}(k)=\hat{\gamma}_{1,2}(k) / \sqrt{\operatorname{Var}\left[\hat{\gamma}_{1,2}(k)\right]}
$$

\footnotetext{
${ }^{11}$ Ramsey and Rothman (1996) suggest that the appropriate values for $m$ and $K$ that should be selected in practice are $m=3$ and $K=5$. The choice of order 3, and similarly degree 5, arguably provides the best compromise value for identifying time reversibility given the degrees of freedom typically available for economic time series.
} 
If $\left\{X_{t}\right\}$ is a stationary sequence of zero mean independently and identically distributed (i.i.d.) random variables then the exact small sample variance of $\hat{\gamma}_{2,1}(k)$ is given by $\operatorname{Var}\left[\hat{\gamma}_{2,1}(k)\right]=2\left(\mu_{4} \mu_{2}-\mu_{3}^{2}\right) /(T-k)-2 \mu_{2}^{3}(T-2 k) /(T-k)^{2}$ where $\mu_{2}=E\left[X_{t}^{2}\right], \quad \mu_{3}=E\left[X_{t}^{3}\right]$ and $\mu_{4}=E\left[X_{t}^{4}\right]$ are replaced by their sample counterparts. ${ }^{12}$ However, this result does not hold where $\left\{X_{t}\right\}$ is serially correlated, as is the case for the data under consideration here, and we therefore follow the recommendations of Ramsey and Rothman (1996) and Rothman (1997) in performing computation of the test statistic's empirical variance by means of Monte Carlo simulation of the hypothetical linear model which generated the data. ${ }^{13}$

Under the null hypothesis of time reversibility the expected value of $\hat{\gamma}_{2,1}(k)$ is zero and, under certain mixing conditions $T R(k)$ is asymptotically distributed as $N(0,1)$, permitting straightforward calculation of probability values associated with rejection of the null. ${ }^{14}$ However, in order to account for possible interdependence among the test statistics for different values of $k$, we follow Ramsey and Rothman (1996) and Rothman (1997) in reporting a portmanteau version of the $T R$ test statistic based on the largest absolute value among individual $T R$ test statistics calculated for $k=1,2, \ldots, K$, which we denote by $T R\left(k^{*}\right)$,

\footnotetext{
12 For further details, see Theorem 2 of Ramsey and Rothman (1996), and for a frequency domain variant of the TR test statistic based upon the bispectrum, see Hinich and Rothman (1998).

13 Under this latter approach an estimate of the variance of the variance of $\hat{\gamma}_{2,1}(k)$ is calculated by fitting a linear autoregressive (AR) model to the data, obtaining an estimate of the innovations variance, and then simulating a series using the estimated AR coefficients and generating a Gaussian error process with zero mean and variance equal to that estimated in the preceding stage. Values of $\hat{\gamma}_{2,1}(k)$ are calculated for each such replication for $N$ replications, where $N=100$, permitting straightforward computation of the estimated variance using the replicated values for $\hat{\gamma}_{2,1}(k)$. If the process is truly linear Gaussian, and time reversible, this is an exact simulation procedure. If the series is truly nonlinear (Type I time irreversible), the linear model constitutes a local approximation to the unknown nonlinear model, but the procedure should nonetheless provide asymptotically unbiased estimates of the variance of $\hat{\gamma}_{2,1}(k)$ in the presence of uncorrelated innovations.

${ }^{14}$ Note that it is a requirement of the $T R$ test statistic that the data possess a finite sixth moment. Chen et al. (2000) have proposed an alternative to the $T R$ test statistic which does not have any moment restrictions. However, as Chen et al. note, their test is not directly applicable to model residuals because it is a test of unconditional symmetry, and cannot therefore be used in order to discriminate between Type I and Type II time irreversibility.
} 
together with the associated probability of rejecting the null of time reversibility for that value of $k$, denoted by $p\left(T R\left(k^{*}\right)\right)$.

Where statistically significant time irreversibility is identified by the portmanteau version of the $T R$ test it may be due to one of two causes. The underlying data generating process may be non-linear even though it has symmetric innovations or, alternatively, a linear model may possess innovations which are drawn from a non-Gaussian probability distribution. The existence of time irreversibility due to the underlying conditional mean model being non-linear is referred to as Type I irreversibility, whilst time irreversibility due to the presence of non-Gaussian innovations in the context of a linear model is described as Type II irreversibility. Both these forms of time irreversibility will lead to rejections of the null of time reversibility for the $T R$-test applied to the raw stationary data.

The test procedure advocated by Ramsey and Rothman (1996) permits discrimination between the Type I and II alternatives based on a further application of the test to the residuals of a linear model fitted to the raw data. If the rejection of the null in the raw data is due to Type I irreversibility (a non-linear model with symmetrically distributed innovations) then the approximation using the linear model should generate residuals which, when the $T R$ test is applied to those residuals, will reject the null of time reversibility symmetry with probability greater than the power of the test. ${ }^{15}$ If, on the other hand, the rejection of the null is due to Type II time irreversibility (a linear model with non-Gaussian innovations) the underlying innovations are i.i.d. and the approximation using the linear model will produce residuals that should be (approximately) time reversible. Thus, under Type I time irreversibility the $T R$-test applied to the linear model residuals should lead to rejections of the

\footnotetext{
15 Note that whilst Type I time irreversibility implies nonlinearity, the converse is not necessarily true, since there exist stationary nonlinear processes that are time reversible (e.g. Lewis, McKenzie and Hugus, 1989). The TR test cannot therefore be considered as equivalent to a test for nonlinearity of unknown form.
} 
null of time reversibility, whilst Type II time irreversibility should not. ${ }^{16}$ To clarify these differing uses of the $T R$-test, and to facilitate tabulation of our results, we denote the $T R$ test resulting from application to the raw data as $T R 1$, and we denote the $T R$ test resulting from application to the approximated linear model residuals by $T R 2$.

In relation to tests of asymmetric behaviour, it is of particular interest that simulation results noted by Ramsey and Rothman indicate that where the values obtained for $\hat{\gamma}_{2,1}(k)$, for low values of $k$ are positive, steepness asymmetry in the form of long slow expansions and short steep declines is evident, whilst where such initial values are negative the asymmetry takes the form of fast sharp expansions and longer gradual declines. Further, Rothman (1990, 1998) demonstrates by Monte Carlo simulation that where Type I irreversibility is identified, the appropriate class of non-linear model to represent the time series can be determined from the pattern of significant $T R$ statistics generated by the $T R 2$ test. Specifically, if the $T R 2$ statistics are found to decline exponentially with $k$ this is indicative of non-linear models of the bilinear (BL) class. However, where the underlying nonlinear model is of threshold form, as is our a priori expectation as discussed in Section I, and of the self exciting threshold autoregressive (SETAR) form in particular, TR2 tests will produce a large significant statistic for $k=1$ but further statistics will fall immediately near to zero for values of $k>1 .^{17}$

\section{Data}

In an effort to ascertain whether time irreversibility is more closely associated with certain disaggregated categories of investment expenditure or with certain industrial groupings, two

\footnotetext{
${ }^{16}$ For more detailed discussion of this test procedure and its rationale, see Ramsey and Rothman (1996). On the uses and possible limitations of the TR test statistic as a guide to model specification tool in application to nonlinear conditional mean and conditional variance model residuals, see Rothman (1999) and Belaire-Franch and Contreras $(2002,2003,2004)$.

17 Note that whilst Type I time irreversibility implies nonlinearity, the converse is not necessarily true, since there exist stationary nonlinear processes that are time reversible (e.g. Lewis, McKenzie and Hugus, 1989). The TR test cannot therefore be considered as equivalent to a test for nonlinearity of unknown form.
} 
sets of investment data are considered here. The first comprises Office for National Statistics (ONS) National Accounts data for aggregate investment across three investment good categories: new building work; expenditure upon vehicles; and other investment. These series cover investment made by all sectors of the UK economy not just the manufacturing sector, and the last of these three categories includes much investment that is often referred to as plant and equipment investment. Two additional categories are also included: total business investment (the combined total of these three investment good categories), and gross fixed capital expenditure. ${ }^{18}$ The National Accounts data for these investment series aggregated by expenditure type is quarterly, seasonally adjusted, expressed in constant 2001 £million prices, and runs from 1966:1-2004:2. ${ }^{19}$

The second group of investment series analyzed are ONS First Release investment series for industry groups. The seven industry groups considered are: fuels; metals; chemicals; engineering; food; textiles; and other manufacturing. Table 1 shows industrial compositions of these industry groups by two-digit standard industrial classification (SIC) codes. This data is also quarterly, seasonally adjusted and expressed in constant 2001 £million prices, but covers the shorter available sample period 1979:1-2004:2. ${ }^{20}$

Whilst non-stationarity due to drift is a pervasive feature of economic time series, and would lead them to necessarily exhibit time irreversibility, the essential question is whether the drift-free stationary components of those process are time reversible. Thus, as emphasized in Section II, the series being tested must be stationary in order for the TR test not to give misleading results, and we therefore employ logarithmic first differences of all series in the

\footnotetext{
18 Whilst the first four of these investment series are net of disposals of capital, gross fixed capital expenditure refers only to acquisitions.

19 ONS series codes (www.statistics.gov.uk): New Building Work (IMKQ); Vehicle Expenditure (IMWB); Other Capital Expenditure (INHM); Total Business Investment (INLN); Gross Fixed Capital Formation (INLN). ${ }^{20}$ ONS series codes (www.statistics.gov.uk): Solid and Nuclear Fuels, Oil Refining (INKZ) ; Metals and Metal Goods (INLC); Chemicals and Man Made Fibres (INLA); Engineering and Vehicles (INKQ); Food, Drink and Tobacco (INKV); Textiles Clothing, Leather and Footware (INKW); Other Manufacturing (JZKM).
} 
test results which follow. ${ }^{21}$

\section{Empirical Results}

Tables 2 and 3 present the results obtained from the application of the TR1 and TR2 tests discussed in Section II to the stationary transformations of the various investment data series described in Section III. ${ }^{22}$ More specifically, Table 2 presents the results of TR1 and TR2 tests for time irreversibility to order $m=3$ and degree $K=5$ applied to the investment series disaggregated by expenditure type, including the standardised test statistics $T R(k)$ for $k=1,2, \ldots, 5$, and the portmanteau version of the $T R$ test statistic based on the probability of rejecting the null of time reversibility for the largest absolute value among individual $T R$ test statistics, denoted by $p\left(T R\left(k^{*}\right)\right)$. Corresponding results for investment disaggregated by broad industrial sector grouping are similarly presented in Table 3.

It is immediately apparent from the TRI test results reported in Panel A of Table 2 that highly significant time irreversibility is present in vehicles expenditure whilst new building work and other capital expenditure are time reversible. However, the aggregate of these three expenditure types, total business investment, is time reversible. In contrast, aggregated gross fixed capital formation is time irreversible. What do these results mean for the patterns observed in the series through the business cycle? The sign of the initial TRl test

\footnotetext{
${ }^{21}$ Whilst not reported here in full, the appropriateness of this transformation is confirmed by the results of Phillips-Perron test statistics which are unable to reject the presence of a unit root in the logarithmically transformed data but are able reject a unit root in the first difference of logarithms, for all the investment series considered. These inferences are also robust to variation in the test equation specification concerning inclusion or exclusion of a trend, constant or both, for the logarithmic data and the differenced logarithmic data. Full details of these unit root test results are available on request from the authors.

${ }^{22}$ Recall from the discussion in Section II that an appropriate linear specification is necessary in order for the significance of the standardized test statistic results to be calculated and the alternative hypothesis of time irreversibility to be tested against the null of time reversibility, as well as in discriminating between Type I and Type II time-irreversibility. In particular, the results reported employ an estimate of the variance of $\hat{\gamma}_{2,1}(k)$ calculated by Monte Carlo simulation using a a linear autoregressive $\operatorname{AR}(\mathrm{p})$ model fitted to the data of order $p$ determined by reference to the Akaike Information Criterion (AIC). Alternative results based on application of the Schwarz (Bayesian) Information Criterion (BIC) which provide qualitatively equivalent results are omitted here in the interest of conserving space, but are available from the authors on request.
} 
statistic is found to be negative for vehicles expenditure which (assuming the investment series are pro-cyclical) would suggest that vehicles expenditure follows a fast up and slow down pattern, whilst the positive sign associated with initial test values for gross fixed capital formation implies a slow up but fast down pattern over the business cycle. The pattern exhibited by vehicles expenditure is therefore most similar to that expected due to irreversible investment whereby firms make 'lumpy' investments, whilst that displayed by fixed capital expenditure is the more akin to the widely perceived asymmetry of the business cycle in general. On the basis of the TR2 test results in Panel B of Table 2 the time irreversibility detected in vehicle expenditure is of Type II form (implying an underlying linear model with non-Gaussian distributed innovations) whilst for gross fixed capital formation the time irreversibility is of Type I form (implying an underlying non-linear model with symmetrically distributed innovations). From the discussion in Section I, a possible causes of Type I time irreversible investment is the lemons' problem, which is likely to be a particularly acute issue in relation to vehicles. In contrast, it is of particular note that the pattern of TR2 test statistics for gross fixed capital formation, which imply an underlying nonlinear time series structure, are broadly indicative of some form of threshold process, and consistent with $(\mathrm{S}, \mathrm{s})$ type models of investment behaviour (Rothman, 1999).

The test results for investment broken down by industry groupings in Table 3 indicate significant time irreversibility on the basis of TRl test results for three groupings, fuels \& oil refining, engineering $\&$ vehicles, and textiles \& leather, whilst the remaining industry groups exhibit time reversible investment patterns (metals \& metal goods; chemicals \& man made fibres; food, drink \& tobacco; and other manufacturing). The oil industry in particular has been used previously as an example of an industry strongly affected by irreversible investment (Paddock 1988), so the finding of time irreversibility for the fuels industry sector 
is not entirely unexpected. ${ }^{23}$ The patterns of investment suggested by the results displayed in Table 3 Panel A for the three industry groups with significant time irreversibility results suggest that for both engineering \& vehicles and textiles \& leather investment follows the slow up fast down dynamic widely accepted as characterising the business cycle. The implications are less clear for fuels \& oil refining where the alternating TR 1 test statistic signs for $k=1,2$ suggests that this may be the only industry grouping with at least the potential for a fast up slow down pattern, as might be expected with irreversible investment, though the presence or absence of this property in this series cannot be definitively asserted by the test values reported. On the basis of the TR2 test results in Panel B of Table 3, Type I time irreversibility is found only for the textiles \& leather industry grouping, with Type II time irreversibility present in the fuels \& oil refining, and engineering \& vehicles industry groups. As with the earlier results for capital formation, the $T R 2$ test results for textiles \& leather show that the largest $T R$ statistic is found for $k=1$ with mostly much reduced statistics for $k>1$ implying that a threshold $(\mathrm{S}, \mathrm{s})$ process may provide an appropriate time series model to describe the investment dynamics of this industry grouping, but the sizable $T R 2$ test statistic for $k=4$ suggests that the most appropriate non-linear representation for this series may not be of specifically SETAR form.

\section{Conclusion}

It has long been suggested that investment may be time irreversible in the presence of a fixed capital adjustment cost component, due to capital being specific to a particular industry or firms' facing a lemons'-type problem in attempting to resell capital, and these rationales have been supplemented more recently by the introduction of the 'option value' of waiting to

\footnotetext{
${ }^{23}$ Indeed, along with other industries based in the primary sector such as mining (Brennan and Schwartz, 1985) and forestry (Morck et al., 1989), where natural resources lend themselves easily to the explanation of the option value of an investment, the oil industry provides one of the 'benchmark' examples of irreversible investment.
} 
invest. However, depending on whether the dynamics governing firm investment decisions and shocks to the firms operating environment are common to an industry (or the macroeconomy) or wholly idiosyncratic, such irreversibilities may or may not be manifest in aggregate investment data. This paper has therefore sought to assess the empirical evidence for time irreversibility in UK investment not only at the aggregate level but according to disaggregation by type of investment expenditure as well as by disaggregation across manufacturing sector groupings, using the time reversibility test methodology of Ramsey and Rothman (1986) and Rothman (1997, 1999). The test statistics reported provide evidence of statistically significant time irreversibility in aggregate gross fixed capital formation, aggregate vehicle expenditure, and the industrial sector groupings covering fuels \& oil refining, engineering \& vehicles, and textiles \& leather. These findings suggest that the irreversibility of investment patterns varies not only from industry to industry but also according to the type of capital being purchased. However, with the exception of gross fixed capital formation (and possibly the textiles \& leather sector grouping), such time irreversibility is mostly attributable to non-linearities in the shocks to the processes governing such investments rather than non-linearities in the underlying data generating process associated with threshold effects consistent with (S,s) type models of investment, with attendant implications for the time series modelling of such processes. In particular, such findings are consistent with the generalized $(\mathrm{S}, \mathrm{s})$ theoretical framework developed by Caballero and Engel (1999). However, it remains possible that the levels of disaggregation entertained here are insufficient to fully reveal the consequences of the irreversible and potentially non-linear nature of investment at firm or plant level, and further analyses might usefully extend our results by considering data at finer levels of disaggregation by sector and expenditure type, and in their combination, data availability permitting. 


\section{References}

Abel, A.B. and Eberly, J.C. (1996) 'Optimal investment with costly reversibility', Review of Economic Studies, 63, 581-593.

Abel, A.B. and Eberly, J.C. (1997) 'An exact solution for the investment and value of a firm facing uncertainty, adjustment costs, and irreversibility', Journal of Economic Dynamics and Control, 21, 831-852.

Akerlof, G. (1970) 'The market for lemons: quality uncertainty and the market mechanism', Quarterly Journal of Economics, 84, 488-500.

Andreano, M.S. and Savio, G. (2002) 'Further evidence on business cycle asymmetries in G7 countries', Applied Economics, 34, 895-904.

Arrow, K.J. (1968) 'Optimal capital policy with irreversible investment', in Wolfe, J.N. (ed.) Value, Capital and Growth: Papers in Honour of Sir John Hicks, Edinburgh University Press: Edinburgh.

Barnett, S.A. and Sakellaris, P. (1998) 'Non-linear response of firm investment to $q$ : testing a model of convex and non-convex adjustment', Journal of Monetary Economics, 42, 261-288.

Belaire-Franch, J. and Contreras, D. (2002) 'Higher-order residual analysis for AR-ARCH models with the TR test', Applied Economics Letters, 9, 749-752.

Belaire-Franch, J. and Contreras, D. (2003) 'Tests for time reversibility: a complementarity analysis', Economics Letters, 81, 187-195.

Belaire-Franch, J. and Contreras, D. (2004) 'A power comparison among tests for time reversibility', Economics Bulletin, 3, 1-17.

Bernanke, B.S. (1983) 'Irreversibility, uncertainty and cyclical investment', Quarterly Journal of Economics, 98, 85-106.

Bertola, G. and Caballero, R.J. (1994) 'Irreversibility and aggregate investment', Review of Economic Studies, 61, 223-246.

Bodman, P. M. (2001) 'Steepness and deepness in the Australian macroeconomy', Applied Economics, 33, 375-382.

Brennan, M. J. and Schwartz, E. S. (1985) 'Evaluating natural resource investments', Journal of Business, 58, 135-157.

Caballero, R.J., Engel, E.M.R.A. and Haltiwanger, J.C. (1995) 'Plant-level adjustment and aggregate investment dynamics', Brookings Papers on Economic Activity, 2, 1-54.

Caballero, R.J. and Engel, E.M.R.A. (1999) 'Explaining investment dynamics in US manufacturing: a generalized (S,s) approach', Econometrica, 67, 783-826. 
Caballero, R.J. and Pindyck, R.S. (1996) 'Uncertainty, investment and industry evolution', International Economic Review, 37, 641-662.

Chen, Y.-T., Chou, R.-Y. and Kuan, C.-M. (2000) 'Testing time reversibility without moment restrictions', Journal of Econometrics, 95, 199-218.

Cook, S. (1998) 'Regional variation in the cyclical asymmetry of UK unemployment', Applied Economics Letters, 6, 543-546.

Cook, S. (2000) 'Alternative diagnostic tests of asymmetric adjustment: a cross-country application and comparison', Applied Economics, 32, 1365-1371.

Cook, S. (2000) 'The alternative asymmetric behaviour of Australian consumers' expenditure', Applied Economics Letters, 7, 349-352.

Cook, S. (2000) 'Asymmetry and non-linearity in UK output', Applied Economics Letters, 7, 459-461.

Cook, S. (2000) 'Seasonal adjustment and the univariate testing of asymmetry', Applied Economics Letters, 7, 649-652.

Cooper, R. Haltiwanger, J. and Power, L. (1999) 'Machine replacement and the business cycle: lumps and bumps', American Economic Review, 89, 921-946.

Corrado, L., Holly, S. and Turner, P. (2001) 'Nonlinearities and inactivity in aggregate investment: some theoretical analysis and time-series evidence', Studies in Nonlinear Dynamics and Econometrics, 5, 261-280.

Dixit, A.K. (1991) 'A simplified treatment of the theory of optimal regulation of Brownian motion', Journal of Economic Dynamics and Control, 15, 657-673.

Dixit, A.K. and Pindyck, R.S. (1994) Investment Under Uncertainty, Princeton University Press: Princeton.

Doms, M. and Dunne, T. (1998) 'Capital adjustment patterns in manufacturing plants', Review of Economic Dynamics, 1, 409-429.

Eisner, R. and Strotz, R.H. (1963) 'Determinants of business fixed investment' In Commission of Money and Credit, Impacts of Monetary Policy, 59-337, Prentice-Hall.

Gale, D. (1996) 'Delay and Cycles', Review of Economic Studies, 63, 169-198.

Gould, J.P. (1968) 'Adjustment costs in the theory of investment of the firm', Review of Economic Studies, 35, 47-55.

Hinich, M. J. and Rothman, P. A. (1998) 'A frequency domain test of time reversibility', Macroeconomic Dynamics, 2, 72-88. 
Jamet, S. (2004) 'Irreversibility, uncertainty and growth', Journal of Economic Dynamics and Control, 28, 1733-1756.

Lewis, P.A.W., McKenzie, E. and Hugus, D.K. (1989) 'Gamma processes', Communications in Statistics - Stochastic Models, 5, 1-30.

Lucas, R.E., Jr. (1967) 'Adjustment costs and the theory of supply', Journal of Political Economy, 75, 321-334.

McDonald, R. and Siegel, D. (1986) 'The value of waiting to invest', Quarterly Journal of Economics, 101, 707-728.

Mitchell, W.C. (1927) Business Cycles: The Problem and its Setting, National Bureau of Economic Research: New York.

Mittnik, S. and Niu, Z. (1994) 'Asymmetries in business cycles: econometric techniques and empirical evidence', in Semmler, W. (ed.) Business Cycles: Theory and Empirical Methods, Kluwer Academic Publishers: Boston.

Morck, R. Schwartz, E. and Strangeland, D. (1989) 'The valuation of forestry resources under stochastic prices and inventories', Journal of Financial and Quantitative Analysis, 24, 473-487.

Mussa, M. (1977) 'External and internal adjustment costs and the theory of aggregate and firm investment', Economica, 44, 163-178.

Olekalns, N. (2001) 'Cyclical asymmetries in Australian macroeconomic data', Applied Economics Letters, 8, 145-148.

Paddock, J.L. Siegel, D.R. and Smith, J.L. (1988) 'Option valuation of claims on real assets: the case of offshore petroleum leases', Quarterly Journal of Economics, 103, 479-508.

Peiró, A. (2004) 'Are business cycles asymmetric? Some European evidence', Applied Economics, 36, 335-342.

Pindyck, R.S. (1988) 'Irreversible investment, capacity choice, and the value of the firm', American Economic Review, 78, 969-985.

Price, S. (1996) 'Aggregate uncertainty, investment and asymmetric adjustment in the UK manufacturing sector’, Applied Economics, 28, 1369-1379.

Psaradakis, Z. (2000) 'P-value adjustments for multiple tests for nonlinearity", Studies in Nonlinear Dynamics \& Econometrics, 4, 95-100.

Ramsey, J.B. and Rothman, P. (1996) 'Time irreversiblity and business cycle asymmetry', Journal of Money, Credit and Banking, 28, 1-21. 
Rothman, P. (1990) 'Characterization of the time irreversibility of economic time series', PhD Dissertation, New York University.

Rothman, P. (1997) 'FORTRAN programs for running the TR Test: a guide and examples', Studies in Nonlinear Dynamics and Econometrics, 1, 203-208.

Rothman, P. (1999) 'Higher-order residual analysis for simple bilinear and threshold autoregressive models with the TR test', in Rothman, P. (ed) Nonlinear Time Series Analysis of Economic and Financial Data, Kluwer Academic Press: Boston.

Rothschild, M. (1971) 'On the cost of adjustment', The Quarterly Journal of Economics, 85, 605-622.

Sensier, M. (2003) 'Inventories and asymmetric business cycle fluctuations in the UK: a structural approach', Applied Economics, 35, 387-402.

Speight. A.E.H. (1997) 'Testing for business cycle asymmetry: some international evidence', Applied Economics Letters, 4, 603-606.

Speight, A. and McMillan, D. (1997) 'Are there asymmetries in consumption?: A closer look', Applied Economics Letters, 4, 241-245.

Stanca, L. (1999) 'Asymmetries and nonlinearities in Italian macroeconomic fluctuations', Applied Economics, 31, 483-491.

Süssmuth, B. (2003) 'Are procyclical lumpiness and asymmetry in capital adjustment dateless phenomena? The case of firms in German industrialization: 1880-1913', Applied Economics Letters, 10, 575-579.

Tong, H. (1990) Non-Linear Time Series: A Dynamical Systems Approach, Oxford University Press: Oxford.

Tzouramani, I. and Mattas, K. (2004) 'Employing real options methodology in agricultural investments: the case of greenhouse construction', Applied Economics Letters, 11, 355-359.

Vandenbroucke, J. (1999) 'General trigger values of optimal investment', Applied Economics Letters, 6, 287-290.

Verbrugge, R.J. (2002) 'Longtitudinal inflation asymmetry', Applied Economics Letters, 9, 261-264.

Wood, A. (2005) 'Investment interdependence and the coordination of lumpy investments: evidence from the British brick industry', Applied Economics, 37, 37-49. 
Table 1

Industrial Sector Composition by Standard Industrial Classification (SIC) 2-Digit Code

\begin{tabular}{|c|c|}
\hline Sector Name (and ONS Code) & 2-digit SIC(92) Industries contained within sector \\
\hline Solid and Nuclear Fuels, Oil Refining (INKZ) & 23: Manufacture of coke, refined petroleum products and nuclear fuels \\
\hline Metals and Metal Goods (INLC) & $\begin{array}{l}\text { 27: Manufacture of basic metals } \\
\text { 28: Manufacture of fabricated metal products, except machinery and equipment }\end{array}$ \\
\hline Chemicals and Man Made Fibres (INLA) & 24: Manufacture of chemicals, chemical products and man-made fibres \\
\hline Engineering and Vehicles (INKQ) & $\begin{array}{l}\text { 29: Manufacture of machinery and equipment not elsewhere classified } \\
\text { 30: Manufacture of office machinery and computers } \\
\text { 31: Manufacture of electrical machinery and apparatus not elsewhere classified } \\
\text { 32: Manufacture of radio, television and communication equipment and apparatus } \\
\text { 33: Manufacture of medical, precision and optical instruments, watches and clocks } \\
\text { 34: Manufacture of motor vehicles, trailers and semi-trailers } \\
\text { 35: Manufacture of other transport equipment }\end{array}$ \\
\hline Food, Drink and Tobacco (INKV) & $\begin{array}{l}\text { 15: Manufacture of food products and beverages } \\
\text { 16: Manufacture of tobacco products }\end{array}$ \\
\hline Textiles, Clothing, Leather and Footwear (INKW) & $\begin{array}{l}\text { 17: Manufacture of textiles } \\
\text { 18: Manufacture of wearing apparel; dressing and dyeing of fur } \\
\text { 19: Manufacture of leather and leather products }\end{array}$ \\
\hline Other Manufacturing (JZKM) & $\begin{array}{l}\text { 20: Manufacture of wood and wood products } \\
\text { 21: Manufacture of pulp, paper and paper products } \\
\text { 22: Publishing, printing and reproduction of recorded media } \\
\text { 25: Manufacture of rubber and plastic products } \\
\text { 26: Manufacture of other non-metallic mineral products } \\
\text { 36: Manufacture of furniture; manufacturing not elsewhere classified } \\
\text { 37: Recycling }\end{array}$ \\
\hline
\end{tabular}

Source: Report on Census of Production - Summary Volume PA1002 (2000) 
Table 2

Time Irreversibility Test Results for Investment Data Disaggregated by Expenditure Type

\begin{tabular}{|c|c|c|c|c|c|c|}
\hline & \multicolumn{5}{|c|}{$T R(k)$} & \multirow{2}{*}{$p\left(\operatorname{TR}\left(k^{*}\right)\right)$} \\
\hline & $k=1$ & $k=2$ & $k=3$ & $k=4$ & $k=5$ & \\
\hline \multicolumn{7}{|c|}{ A: TR1 Time Irreversibility Test Results } \\
\hline New Building Work & -1.4753 & -1.3398 & 2.0841 & 1.0973 & -2.0120 & 0.1380 \\
\hline Vehicle Expenditure & -3.3174 & 0.2420 & 0.0853 & -3.1048 & -0.4162 & $0.0060 *$ \\
\hline Other Capital Expenditure & -0.5305 & -0.0965 & -1.2424 & 2.2078 & -0.4474 & 0.1290 \\
\hline Total Business Investment & -1.0487 & -0.0690 & -0.2170 & 0.8467 & 0.7844 & 0.7560 \\
\hline Gross Fixed Capital Formation & 3.0892 & -0.5462 & 0.6849 & 1.6535 & -1.6465 & $0.0170 *$ \\
\hline \multicolumn{7}{|c|}{ B: TR2 Time Irreversibility Test Results } \\
\hline New Building Work & 0.1331 & -0.5145 & -0.7437 & 1.3344 & 0.4168 & 0.6520 \\
\hline Vehicle Expenditure & -1.2675 & -1.6807 & -0.1882 & -1.0035 & -0.1335 & 0.4120 \\
\hline Other Capital Expenditure & -0.5202 & -0.0571 & -1.2698 & 2.5412 & -0.3935 & 0.0600 \\
\hline Total Business Investment & -1.7372 & -0.4905 & -0.7025 & 1.0456 & 1.0495 & 0.3880 \\
\hline Gross Fixed Capital Formation & 3.5874 & 0.5365 & 0.0482 & 0.9752 & -0.7617 & $0.0040 *$ \\
\hline
\end{tabular}

Notes: TR1 refers to the time reversibility standardized $T R(k)$ test statistic of Ramsey and Rothman (1996) applied to the stationarity adjusted logarithmic data for $k=1, \ldots, 5$ under the null hypothesis of time reversibility. TR2 refers to the portmanteau version of the standardized time reversibility test statistic applied to the residuals of an AR model of order determined by the AIC criterion as a discriminating test between Type I and Type II time irreversibility under the null of time reversibility in those residuals. In both cases $p\left(T R\left(k^{*}\right)\right)$ refers to the p-value for rejection of the null associated with the portmanteau version of the test based on the largest absolute value of the standardized test statistics (indicated in italics). An asterisk denotes portmanteau test significance at the $5 \%$ level. Where only significant TR1 portmanteau test significance holds Type II time irreversibility is indicated (implying an underlying linear model with nonGaussian innovations), where both TR1 and TR2 portmanteau test significance holds Type I time irreversibility is indicated (implying an underlying non-linear model with symmetrically distributed innovations), and where neither statistic is significant the process is fully time reversible (and linear). For further details, see Section II and Ramsey and Rothman (1996). 
Table 3

Time Irreversibility Test Results for Investment Data Disaggregated by Industry Group

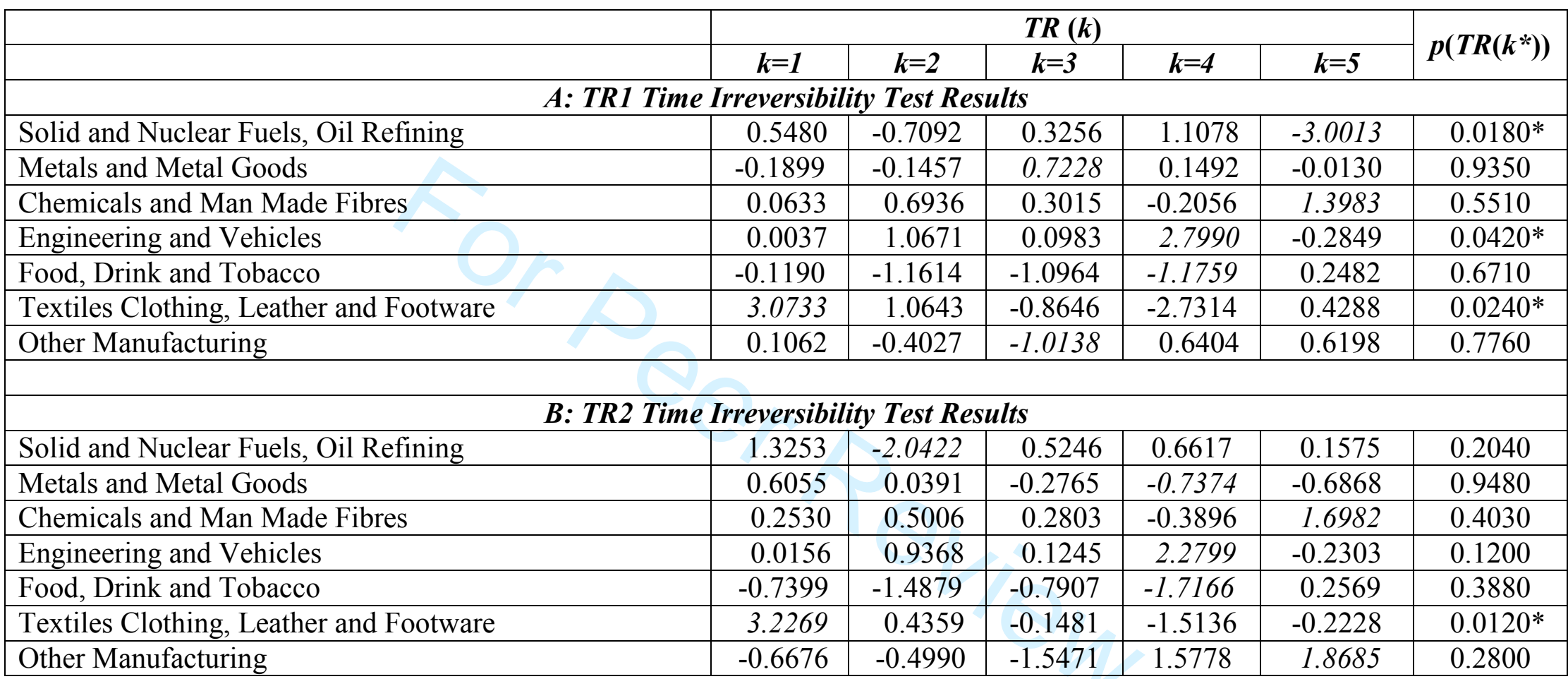

Notes: TR1 refers to the time reversibility standardized $T R(k)$ test statistic of Ramsey and Rothman (1996) applied to the stationarity adjusted logarithmic data for $k=1, \ldots, 5$ under the null hypothesis of time reversibility. TR2 refers to the portmanteau version of the standardized time reversibility test statistic applied to the residuals of an AR model of order determined by the AIC criterion as a discriminating test between Type I and Type II time irreversibility under the null of time reversibility in those residuals. In both cases $p\left(T R\left(k^{*}\right)\right)$ refers to the p-value for rejection of the null associated with the portmanteau version of the test based on the largest absolute value of the standardized test statistics (indicated in italics). An asterisk denotes portmanteau test significance at the 5\% level. Where only significant TR1 portmanteau test significance holds Type II time irreversibility is indicated (implying an underlying linear model with nonGaussian innovations), where both TR1 and TR2 portmanteau test significance holds Type I time irreversibility is indicated (implying an underlying non-linear model with symmetrically distributed innovations), and where neither statistic is significant the process is fully time reversible (and linear). For further details, see Section II and Ramsey and Rothman (1996). 